\title{
Some reflections on the legitimacy of international trial justice
}

\author{
Ralph Henham \\ Nottingham Law School, Nottingham Trent University, Burton Street, Nottingham NG1 4BU, UK
}

\begin{abstract}
This paper addresses a number of interrelated conceptual difficulties which impact adversely on the ability of international criminal trials to deliver outcomes perceived as legitimate by victims and communities in post-conflict states. It begins by exploring the extent to which those moral justifications for punishment espoused by international courts are instrumental in marginalizing the aspirations for justice of victims and victim communities, and suggests how a greater appreciation of the sociological context of punishing international crimes can contribute towards an improved understanding of normative practice. The paper then examines the relationship between perceptions of international crime and punishment, and the broader issue of whether international criminal law provides an appropriate normative structure for giving effect to those universal humanitarian values concerned with punishment in an increasingly pluralistic world. Finally, the paper considers how the theory and practice of punishing international crimes can more effectively satisfy both local and global aspirations for post-conflict justice through enhancing the transformative capacity of international criminal trials.
\end{abstract}

\section{Introduction}

The main contention of this paper is that the resolution of the substantive and procedural difficulties faced in punishing international crimes such as genocide and crimes against humanity can only be advanced if we consider them in the broader context of the moral arguments which inform the penality of international criminal justice (ICJ) and their wider sociological significance. In suggesting this, the paper does not advocate particular moral principles or ideology for ICJ, rather it argues that the normative frameworks of international trial justice should enable connections to be made between those moral values which inform ICJ and the perceived legitimacy of trial outcomes. This contention is not prescriptive in suggesting which moral values are relevant, or in attributing legitimacy to particular trial outcomes; nor does it suggest that ICJ should exist as a vehicle for transforming particular moral principles into empirical reality or vice versa.

The argument does not imply any acceptance of the naturalistic fallacy cautioned by Finnis (1980) by suggesting that the moral principles which should govern ICJ can be 
derived from the empirical analysis of existing normative practice. On the contrary, the approach adopted is intended as complementary; being premised on the notion that the objective validity ${ }^{1}$ of morally significant propositions can only be tested against empirical fact and the operation of those social processes which they hope to influence. Therefore, I argue that reaching a better understanding of the extent to which normative propositions in ICJ actually dictate, or are reflected in, empirical fact is an essential endeavour for social theorizations of ICJ practices. Recognition of the legal, social and political contexts in which ICJ takes place is necessary not only to identify and understand how competing interests manifest themselves in processual activity, but also to provide validity to the analysis and evaluation of competing moral justifications for punishment.

The paper focuses deliberately on the process of punishment in international criminal trials. It argues that international trial justice has the potential to act as a transformative mechanism; one that gives effect to moral values through the consistent application of punishment norms delivered within an appropriately flexible ideological and normative framework (Findlay and Henham, 2005). Unlike much recent commentary which suggests a limited role for trial justice (Roche, 2005: 572), this paper envisages the development of international trial penality as pivotal to establishing the long term credibility of ICJ by extending its potential for promoting peace and reconciliation in post-conflict societies.

International sentencing praxis, as currently exemplified by the United Nations International Criminal Tribunals for the Former Yugoslavia (ICTY) and Rwanda (ICTR), ${ }^{2}$ is essentially concerned with operationalising particular penal justifications, more especially, those of retribution and deterrence (Henham, 2003). As Hart (1968) suggests, unlike principles of criminal liability which are primarily concerned with the determination of legal responsibility, the practical engagement of philosophical justifications for punishment through discretionary decision-making characterizes the criminal responsibility of the trial verdict by giving distributive effect to the principles for determining justice. International trial justice similarly engages directly with those normative paradigms that give effect to the rationalisations for punishment set out in the foundation instruments of the international courts and tribunals and judicially interpreted in their sentencing jurisprudence.

Whereas a purely legal doctrinal approach would not consider the relationship between normative analysis and social context, or purport to expound on the moral integrity of punishment or the subjective impact of sentencing on behaviour, the approach taken in this paper differs because it sees essential connections between understanding the moral significance of those reasons which inform action and the actions themselves. Consequently, it argues that if international trial justice is to signify anything this must

\footnotetext{
${ }^{1}$ The meaning of this expression remains ontologically conjectural; see Roberts (2002: 547).

2 The ICTY was established by United Nations Security Council Resolution 827 of $25^{\text {th }}$ May 1993 , UN Doc.S/RES/827. The ICTR was established by United Nations Security Council Resolution 955 of $8^{\text {th }}$ November 1994, UN Doc. S/RES/955.
} 
involve explanations of how its normative process can effectively reflect the moral significance of punishment and thereby hope to influence social behaviour following social conflict and war.

In order to realize the capacity for sentencing norms (whether local or global) to shape or reinforce modalities for understanding the social reality of punishment, and thereby appreciate the moral power of law (Cotterrell, 1998a: 182), we need to conceptualise legal thought and decision-making as a process (Henham, 2001: 266). This does not require law's 'reality' to be subsumed or distorted by sociological interpretations, but rather an acknowledgement that sociological insights are capable of providing conceptual settings which facilitate our understanding of different legal discourses (and systems) and enable us to comprehend how each discourse constructs 'inside' and 'outside' from the internal points of view of both law and sociology (Nelken, 1998: 419). Such understandings are vital in assessing the actual or potential moral worth of international humanitarian law; for example, whether the moral legitimacy of the international penal regime, as constituted, is capable of reflecting value pluralism and moral conjecture. Also significant is our conceptual capacity to link ICJ as a generalised expression of morality with the existence of more collectively held notions of morality as expressed in civil society, such as communitarianism.

Contemporary notions of criminality, acceptable forms of punishment and concepts of justice each determine important aspects of the penality of ICJ that have been mediated through the penal practices of the international criminal tribunals. Garland's (1990: 253) point regarding the signifying nature of penality has special resonance in suggesting that ICJ should be reflective of generally understood cultural meanings of crime and punishment. Thus, the significance of law's transformative capacity may be considerable in its implications for penality, both in terms of its institutionalisation and in the forms of punitive control exercised over citizens within the international context. This observation recognises that the determination of power relationships within and between states may serve to marginalize the universality of human and minority rights in victim communities and de-contextualise punishment administered internationally (Drumbl, 2000).

These considerations are reflected in the development of this paper. The argument is developed in several stages designed to draw together those contingent themes which it is argued need to be addressed in the process of developing new rationales and normative structures for ICJ. ${ }^{3}$ It is for this reason that the paper begins by making the point that the penality of ICJ is currently weighted heavily towards retribution and deterrence as primary justifications, arguing that the credibility of ICJ largely depends on the perceived moral legitimacy of the justice it dispenses and suggesting that this issue is inadequately addressed within the current penal paradigm. The role of criminological theory is envisaged as facilitating our understanding of what 'legitimacy' actually signifies in this context. More specifically, since justice and morality are relative, the only way we can approximate understandings of what the idea of justice represents in the minds of the citizens of post-conflict societies is to devise concepts and methodologies which have the

${ }^{3}$ Of necessity, the paper offers a thematic rather than detailed analysis of each of the issues raised. 
capacity to get as close as possible to representing their feelings about justice for the perpetrators of international crimes (Kiza and Rohne, 2005). Accepting that the ultimate purpose of the analysis is to stimulate debate about the punishment ideology and practice of international trial justice (Findlay and Henham, 2005), the paper then questions the extent to which current conceptualisations of ICJ are capable of responding to the epistemological challenge of recognising and giving effect to pluralistic justice claims, and points to areas where new conceptual tools are necessary. The argument then develops this theme of change by suggesting how judicial discretionary decision-making sites within international trials could become the instrumental focus for delivering a more representative and 'legitimate' form of ICJ.

\section{Moral Arguments}

The suggestion that some kind of moral justification should inform the penality of international criminal trials requires further elaboration. If we assert that pragmatic reasons for action (Jorgenson, 2002) do not provide sufficiently moral justifications for the practice of punishment, what exactly do we mean? Although the exercise of free will may be deemed by certain utilitarian measures to be intrinsically good, and bring undoubted benefits, my objection to the elevation of pragmatism to the status of a philosophical justification for punishment lies is the fact that it eschews any clearly defined purpose for restricting the free will of others, except that of assessing the value of actions in terms of their practical benefits. ${ }^{4}$ Furthermore, promoting the notion of 'pragmatism' as an ideological imperative merely serves to endorse existing forms of hegemony and social control since it does not espouse any rationale for action beyond that which favours ends over means.

It may be countered that the sense in which we refer to pragmatism in the context of international penality is one which regards the largely unfettered exercise of wide discretionary powers as inherently beneficial because it gives judges the opportunity to individualise penalities within the broader context of what are generally regarded as the traditional concerns for punishment; namely, retribution, deterrence, rehabilitation and social protection. It is broadly assumed that these justifications, when rationalised in individual cases, legitimise the exercise of discretionary power and, therefore, that they have the ability to inform choices which may be characterised as either right or wrong. However, herein lies the paradox for international trial ideology. ${ }^{5}$ Even at the national level, value pluralism militates against the possibility that citizens can empathise in any collective moral sense with those ideologies that inform penal policy and practice. ${ }^{6}$ The globalisation of such conjecture magnifies the disjunction between what international penality actually represents and the extent to which international punishment conforms to

\footnotetext{
${ }^{4}$ For Mill the beneficial consequences of liberty would outweigh any justification for punishment unless the latter satisfied moral requirements which were held collectively; see Acton (1972: 55).

${ }^{5}$ 'Ideology' is not used here in the pejorative sense of implying a particular political philosophy but merely to suggest an underlying rationale or purpose.

${ }^{6}$ As Raz argues, where value pluralism exists there is no moral or other reason to favour one over the others; (Raz, 1994: 338).
} 
definitions of what may be regarded as 'right' or 'just' by citizens globally, especially those of states afflicted by social conflict and war. If the philosophical justifications which inform international penality are to underpin a coherent system of norms for regulating conduct they should allow for the possibility of penal outcomes that conform more readily with characterisations of 'justice' recognised as legitimate by the 'international community' as a whole, especially citizens of post-conflict states

In broader terms, it may be argued that international criminal trials should have a truth-finding function which is consistent with providing penal outcomes that recognise more particularly the pluralistic demands for justice of those significantly affected by conflict and breaches of international humanitarian law. Crucial to the achievement of this goal is the moral characterisation of whatever punishment ideology happens to inform the penality of international criminal trials. ${ }^{7}$ If we take the punishment of genocide, for example, the notion that the international community has a moral right to inflict retributive punishment on its perpetrators, or that there are intrinsic moral benefits to be derived from such infliction, does not tell us how we are to measure the degree of suffering that might be appropriate to assuage the commission of such a heinous crime, or whether retributive punishment can, in any event, as Hampton (1988: 125-126) claims, effectively re-assert the 'appropriate' balance between competing moral values.

Furthermore, such retributive balancing of moral claims is crucially undermined by procedural devices like plea agreements, ${ }^{8}$ which impact directly on how harm and culpability are assessed for the purposes of determining the seriousness of crimes in specific cases. The practice of discounting sentences in return for guilty pleas (whether in plea agreements or not) is hardly convincing where such techniques are used to support avowedly systemic interests under the guise of individualised sentencing. When the measure of retribution is itself highly questionable, sentence reduction for such crimes may be seen as morally indefensible to many. ${ }^{9}$ It is, therefore, surely pertinent to question how such self-serving devices as plea agreements can be morally justified in the case of those indicted for the 'crime of crimes'. ${ }^{10}$

Where individualisation exists in a retributive context the potential utility of procedural norms are commonly restricted by considerations such as proportionality and desert, particularly as regards the extent of their ability to serve social ends like reconciliation and reparation for victims in post-conflict societies. Since the focus for individualism in sentencing is by definition the individual, rather than the social, individualised punishment carried out within the context of a retributive trial rationale is less able to embrace consequentialist themes.

\footnotetext{
${ }^{7}$ For discussion of how different punishment rationales might influence the penality of international criminal trials see, Henham (2003: 64).

${ }^{8}$ As does the use of parole or other mechanisms (judicial or administrative) which carry the potential for sentence modification.

${ }^{9}$ See, for example, in England, the Home Affairs Select Committee's comments on the Sentencing Guidelines Council's (2004) proposed guidance regarding the use of guilty plea discounts and their impact in murder cases.

${ }^{10}$ In terms of truth-finding, arguably this is bargained away along with claims of genocide, and the chance of establishing that what happened elsewhere also amounted to genocide (Henham and Drumbl, 2005).
} 
Furthermore, any claimed communicative or educative function for retributive punishment is rendered largely meaningless where the ideologies and structures which sustain it are not accorded any degree of moral legitimacy. As Hudson (1996: 51) suggests, communicative theory is deficient as a general justification for punishment, since it fails to offer reasons for moral education and reconnection with communitarian values. ${ }^{11}$ For communicative theory to work there should be a realisation that the ideology and norms of punishment must relate to the legal and moral contexts of action so criminalized. As Norrie (2000) suggests, such a relational model of justice is necessary to appreciate the connections between responsible individuals and communities, so that punishment is envisaged as part of that shared experience.

International trial ideology as presently constituted is predicated upon the notion of retribution as an intrinsically justifiable moral principle (Henham, 2003), whereas consequentialist notions are regarded as morally acceptable on the basis that they reflect a moral duty on the part of the international community to maximise what are perceived to be the potential benefits of international punishment. However, I would argue that the credibility of the trial as a structural context for the transformation of moral principles into normative guides for action depends upon its ability to reconcile such competing moral claims for justice. This aspiration requires ideological underpinning and norms that favour the positive deployment of judicial discretionary power to facilitate outcomes commanding moral acceptability because they are forged in pursuit of achieving goals of peace and reconciliation, rather than vindication, exculpation and condemnation (Findlay and Henham, 2005).

\section{Crime, Punishment and Legitimacy}

It has been suggested that a significant role for criminological theory in helping us to understand the significance and meaning of legitimacy in ICJ would be to suggest analytical frameworks that help to identify and explain the links between the causes of those actions claimed as breaches of international criminal law and their effective punishment. ${ }^{12}$ However, it is seemingly problematic for ICJ to envisage any relationship between these variables in conventional terms. The labelling of deviant behaviour as crime and the perceived appropriateness of particular modes of punishment are normally connected instrumentally because the apparatus of state punishment fixes individual criminal responsibility and its penal consequences. Further, whatever the crime (or its seriousness), the justifications for punishment and their effects depend upon the perception that penal effectiveness is somehow related to the aims of punishment. ${ }^{13}$ Criminological theory therefore suggests that it is only through comprehending the

\footnotetext{
${ }^{11}$ Furthermore, as von Hirsch (1993: 73) opines, the state is not entitled to use its coercive powers to endeavour to induce moral sentiments.

12 'Effective' is used here in a neutral sense, without implying any connection to particular philosophical justifications for punishment.

${ }^{13}$ Whether these are based on retributive or consequentialist aspirations.
} 
causes ${ }^{14}$ of criminality that we can effectively address the appropriateness of penal solutions. This relationship of cause and effect is operationalised in varying degrees through the ideology, policy and praxis of criminal justice in all its forms.

For international crimes the philosophical bases for penal action are fragmented and illusory. The ideology of crime causation is globalised and penal solutions are worked through against incomplete and partial understandings of the causes of social conflict and war and the significance of individual criminal responsibility (Akhavan, 2001). The notion of individual responsibility itself may well be irrelevant to perceptions of what constitutes justice for acts of genocide or other international crimes in post-conflict societies, or particular groups within them. ${ }^{15}$ As I suggest, the transformative capacity of international trial justice may be significantly curtailed by the disjunction that exists between the ideology of ICJ and the perceived legitimacy of its outcomes. Consequently, the attribution of specific claims for international punishment (as currently practised) based upon the alleged effects of individualised punishment may be equally spurious and unsustainable. Broad assertions about the capacity for particular penal solutions worked out through the trial to satisfy the justice demands of victims and communities may well remain remote from the real aspirations for justice of the indigenous populations of postconflict states.

Without doubt, the success of strategies aimed at establishing peace through reconciliation and reconstruction in post-conflict societies is necessarily contingent upon the impact of hegemonic power. However, it is also dependant on the extent to which discourses of 'truth' can be taken to contribute to the search for justice. When the legitimacy of international trial justice is called into question because it fails to satisfy pluralistic demands for justice in post-conflict states, it seems sensible to argue for a repositioning of trial ideology so that it is more capable of engaging with pluralistic justice demands. To so argue suggests a belief in the capacity of trial outcomes to provide discourses of truth through which competing dimensions of justice can be satisfied from within post-conflict societies.

However, the arguments are by no means straightforward. For example, Lyotard's (1988) insistence on the non-commensurability of discourses suggests that different forms of rationality cannot be accommodated through the creation of some kind of universal truth such as that represented by ICJ. Certainly, Lyotard might suggest that the truth of the trial narrative as the prevailing discourse should itself be challenged in an attempt to discover how dominant rationalities operate to exclude or restrict competing justice claims, whilst leaving unclear the basis upon which it is possible (if at all) to engage with relative accounts of justice.

Notwithstanding, writers such as Levinas (1989) and Baumann (1993) argue convincingly that prioritising responsibility to others should provide the foundation for moral relationships and so form the basis upon which the development of norms of

\footnotetext{
${ }^{14}$ 'Cause' is not used here in any positivistic sense to support the case for theoretical or methodological determinism.

${ }^{15}$ As in the Rwandan genocide, where tribal affiliation was the crucial signifier
} 
justice approximating some degree of rational consensus might be developed. So, whilst Habermas (1992) might believe in the possibility of objective universal standards of justice, deconstructionists argue for pluralistic and phenomenologically sensitive interpretations of the relationship between law and justice. The significance of this debate in terms of reconfiguring the relationship between international trial ideology and penal practice has considerable resonance because it challenges the moral legitimacy of engaging with externalised representations of law as justice, questioning whether the normativity of law can in any real sense be represented universally. ${ }^{16}$

However, as Norrie (1996; 2000) suggests, much depends on our capacity to explore the relational contexts of ICJ in order to appreciate exactly how it is that understandings of what constitutes justice in specific contexts can be derived from appreciating the relationship between individual responsibility and communitarian needs. Findlay and Henham (2005) argue that such deep contextual knowledge can be operationalised to broaden the relevance and legitimacy of international trial justice. They argue that this can be achieved following a repositioning of international trial ideology and its normative frameworks towards a model of trial justice which favours the reconciliation of retributive and restorative norms. Such a move requires concerted international commitment towards much greater inclusivity; especially the will to empower victims and communities by restoring their engagement with international forms of justice. This will enable them to contribute effectively to the international criminal trial process and its outcomes, rather than allowing the institutions of ICJ to perpetuate their exclusion through the effective denial of those rights and demands perceived by citizens of postconflict societies to be justifiable.

\section{The Purpose of International Criminal Law}

Advancing the case for relational justice in punishing international crimes such as genocide presupposes a degree of agreement as to those interests the law of genocide is designed to protect and the nature of the moral arguments which inform the use of international criminal law to support the achievement of such aspirations. ${ }^{17}$ Contemporary criminal law theories are often of little assistance in answering the first question because they fail to elaborate relevant taxonomies of interest or address the determinants of inclusion and exclusion relative to particular socio-cultural contexts. ${ }^{18}$ Hence, although it makes perfect sense to talk, as Gross (1979) does, about what 'ought' to constitute the concerns of the criminal law in terms of preventing violations of personal or governmental interest, sensibility, and collective welfare, the simple listing of such interests does not provide us with the means for developing particular understandings of how they can be identified and protected in particular situations. ${ }^{19}$

\footnotetext{
${ }^{16}$ This is seen most vividly in Morrison's (1997) description of the Holocaust.

${ }^{17}$ However, as Raz (1994: 330) cautions, the idea that there exists some kind of external moral hierarchy which governs instances of when individuals (and presumably, social groups) regard reasons as moral or not (and to what extent) is wrong.

${ }^{18}$ See, for example, Walker's (1972: 41) list of purposes for the criminal law.

${ }^{19}$ This is clearly evidenced in most national jurisdictions by wide variations in the use of the criminal law to protect vulnerable individuals such as the young, the elderly, and the mentally ill.
} 
Similarly, with international crimes such as genocide, whilst the expressed purpose of trial justice is to ensure that 'the most serious crimes of concern to the international community as a whole [do] not go unpunished ...' and a determination 'to put an end to impunity for the perpetrators of these crimes ..., ${ }^{20}$ substantive offence requirements take no account of the cultural and social contexts of their future application. ${ }^{21}$ In sum, a purely descriptive and de-contextualised paradigm for identifying international justice interests is of marginal utility in helping us to promote rational penal objectives. ${ }^{22}$

Such deficiencies may arguably be countered by testing the moral resonance of law and reflecting moral values more effectively in the framing of substantive offence definitions. For example, we might begin to explore this question by evaluating those arguments and paradigms which suggest alternative moral purposes for sanctioning breaches of international criminal law. Such approaches raise issues extending far beyond purely doctrinal questions concerned with the validity of law, or whether international criminal law can necessarily claim legitimate authority. Raz (1979; 1994: ch 9), for example, argues that the legitimacy of authoritative directives stems from their recognition as such, maintaining also that the processes of authoritative reasoning should be autonomous. It is certainly questionable whether Raz's rules of recognition would be satisfied in post-conflict states such as Bosnia or Rwanda, where ethnic divisions and value pluralism persist. However, whereas Raz's argument suggests a basis for establishing the relative autonomy of legal reasoning from moral considerations, he is not concerned with the actual efficacy of authoritative directives, or the sociological impact of value pluralism and moral relativism as reflected in the ambivalence accorded to international trial justice.

The moral resonance of law as a sanctioning process can be evaluated against particular justice paradigms and tested empirically (subject to methodological limitations). For example, classical liberal theory, which has provided one such paradigm since the Enlightenment (Radzinowicz, 1966), envisages a distinctly minimalist role for retributive punishment and advocates an interventionist approach to crime control (Beccaria, 1995). This kind of contractual link between citizen and state is continually negotiated and refined, but it is, above all, relational in the sense that it is built upon a continuing and reciprocal balancing of power relations and the constantly changing need to adjust the state apparatus of social control. ${ }^{23}$ Similarly, utilitarian and communicative theories are also predicated on instrumental notions of law and its pedagogical capacity. Consequently, the social significance of harm and the appropriateness of penal responses can be seen to correspond with readily identifiable (and certain) moral principles.

\footnotetext{
${ }^{20}$ Preamble to the Rome Statute of the International Criminal Court (1998, as amended)

${ }^{21}$ Indeed, they are normally framed in response to past atrocities.

${ }^{22}$ Rationales for punishment are not elaborated in the foundation instruments of the ad hoc Tribunals or the ICC.

${ }^{23}$ Unfortunately, it failed to consider the relationship between social inequality on crime causation or recognise its discriminatory effects on the exercise of individual rights and freedoms.
} 
Thus, moral assumptions about penal efficacy are often employed instrumentally to justify a 'principled' interference by the state with the liberty of individual citizens, thereby investing punishment with a veneer of moral legitimacy. It might be argued therefore, that to be legitimately represented institutionally, punishment should be based on a commonly held social belief in its moral virtue; such a belief being firmly grounded in a collective conviction that there exists a moral duty to criminalize certain forms of behaviour. This kind of approach is diametrically opposed to the kind of denunciatory theory advocated by Stephen, the Victorian judge and historian, for example, who, in Hart's (1968: 169) words, 'insisted that the criminal law did, and should operate to 'give distinct shape' to moral indignation'. The reason for this is because the moral virtue of the criminal law is derived from the wider social function to be performed by asserting commonly held values about the moral acceptability of particular kinds of behaviour. In other words, it is essentially consequentialist.

A significant problem for contemporary forms of criminal justice is whether it is indeed possible to recognise or measure degrees of moral opprobrium in morally pluralistic societies, leaving aside the question of whether or not it is possible to give them effect. I would argue that there is at least a moral duty to use the criminal law in such a way as to re-enforce communitarian values instead of endorsing other rationales for social control. Better this than to leave the question of intervention to the pragmatists who will consider only whether there is something useful to be gained by invoking it. This can lead to a hegemonic criminal justice policy driven by discriminatory aims of domination and control, rather than objectives informed by consequentialist aspirations like reconciliation and resolution.

Whilst ending impunity for gross breaches of international humanitarian law is universally regarded as a virtuous moral principle, the perceived legitimacy of international trial justice can be portrayed as a culturally relative and morally conjectural issue Arguing in favour of a moral basis for the legitimacy of ICJ entails not only establishing the case for change, but also poses a potentially much more difficult question regarding the extent to which ICJ can be taken to represent any kind of international moral order. The issue to be explored relates, not to the validity of competing moral claims to punish, ${ }^{24}$ but rather the degree to which the capacity exists to conceptualise and promote competing moral claims for punishment in the international sphere. In this respect, Durkheim's (1982; 1984) assertions relating to the 'normality of crime' and the nature of 'collective sentiments' appear pertinent, and might lead to us to reflect upon the proposition that the function of punishment as expressed in sentencing praxis is to promote social solidarity through the recursive re-affirmation of societal values; in particular, to reflect and re-affirm society's moral opprobrium regarding particular acts or omissions defined as crime or deviance.

However, the crucial point about international forms of punishment concerns the nature of the paradox between the symbolic and the actual. The Durkheimian analogy is patently unsustainable in an international or comparative context without further elaboration, because it implies that any conceptualisation of international punishment

${ }^{24}$ Essentially a study of moral relativity. 
should be concerned to establish some form of linkage between individual morality and manifestations of the collective conscience, as represented by some form of global penality. I would suggest that such linkage, as presently constituted, may exist in form and rhetoric, ${ }^{25}$ but not in substance. This is because, except for those affected (directly or indirectly) there is no immediate and actual 'significant other', either in terms of 'victim' or 'community', which can provide the focus for any kind of constructive engagement between individual morality and ICJ. ${ }^{26}$ It is also because the creation and operational reality of international regulatory structures such as international tribunals and courts reflect compromises between the values and norms of different legal and social cultures. Consequently, although the foundation instruments of international trial institutions embody apparently common goals there is often underlying disagreement in rationalising these objectives which manifests itself in practice. This frequently has the effect of obfuscating and impeding pluralistic aspirations for justice in the sentencing of routine cases. I would argue that, since the structures of ICJ are not facilitative, in the sense of giving obvious effect to penal objectives which are immediately relevant for citizens of the world, they are not integral to everyday social life in the same way that domestic penal law is regarded as necessary to maintain civil society. There is no mutual dependency as between citizens and the legal authority, nor any apparent or actual linkage between universal aspirations for justice and the relative reality of ICJ.

As Roberts and McMillan (2003: 329) caution:

Durkheim's characterisation of legal prosecution and punishment, as society's 'collective conscience' responding to criminality's symbolic assault on the normative order, retains considerable contemporary resonance. The reaffirmation of a symbolic penal community, generating public allegiance to a system of norms and popular acceptance of coercive measures for their enforcement, may be significant ingredients in the legitimacy and longterm stability of a criminal justice system. Yet in the international setting, a global community of penal sentiment is elusive and probably, at this time, illusory.

The limitations of Durkheim's theorising are well-known (Garland, 1990); in particular, his apparent failure to account for the pluralistic nature of the moral order, and the fact that law and state action is a function of political domination rather than an expression of collective sentiments and, consequently, represents a limited consensus for the basic regulation of the social order. Yet, the significance of Durkheim for the present argument relates to his attempt to theorise the functional significance of moral consensus as expressed in law's normative characteristics, and the suggestion, therefore, of a moral justification for their enforcement. ${ }^{27}$ Notwithstanding, this insight has to be set against the fact that moral pluralism is a reality of the new world order. In Durkheimian terms, the notion of the collective sentiments as representing some kind of universal or integrated world morality is clearly irrelevant for postmodern western liberal

\footnotetext{
${ }^{25}$ For example, the Preamble to the ICC Statute evokes the notion of a 'global community' - 'Conscious that all peoples are united by common bonds, their cultures pieced together in a shared heritage ......'

${ }^{26}$ The only instinctive human feelings which could be said to hold some kind of universal attachment relate to the need for retributive punishment.

${ }^{27}$ Elsewhere I have suggested that a reciprocal theorisation might envisage rights principles as deriving their moral authority from some collective expression of communitarianism; Henham (2000: 254).
} 
democracies, which are predominantly secular and pluralist, and where the autonomy of the individual is paramount. Even at this national or domestic level, what states purport to achieve in terms of social control through punishment is frequently symbolic. ${ }^{28}$ This disjunction between policy and reality is probably even greater at the global level, where the only collective sentiments likely to be invoked will be through the symbolism and rhetoric associated with retributive justice.

An interesting and related aspect of this theorising concerns Durkheim's notion of individualism (Cotterrell 1999: 202), and its implication that individual collective concern for others as a moral imperative is a significant legitimation for national and international human rights movements. Cotterrell maintains that the value system of individualism envisaged by Durkheim can be conceptualised as sustaining a shared moral culture which transcends national boundaries. The difficulty remains in envisaging the moral basis upon which law's authority is claimed to rest in terms of shared beliefs or sentiments; how to identify the transnational values of individualism in forms of international regulatory power such as structures designed for the implementation of international penal norms purporting to be grounded in principles of fairness and justice.

Nevertheless, the important theoretical insight which Durkheim's sociological positivism provides is one which clearly acknowledges law as a regulatory mechanism sensitive to moral reasoning and the need for pluralistic structures which 'provide moral meaning in conditions of modern social complexity'(Cotterrell, 1999: 226). Hence, although, as Roberts and McMillan (2003: 329) suggest, we may be far from realising the aspiration of a shared global moral consensus to underpin international principles for criminal justice, the significance of Durkheim's theorising for understanding international penality lies in its potential to suggest the basis for a conceptual framework which considers the relationship of law and moral action in context.

Conceptualisations of ICJ must also draw lessons from the changing contexts of governance and social control within state entities. As Garland (1996) suggests, through the process of 'responsibilization', where certain state functions such as crime control have become unattainable, the state/citizen relationship has been reconfigured through policy objectives designed to shift accountability. Similarly, Pratt (1998) describes how the relationship of mutual dependence and trust built up between citizens and state in western democracies during the nineteenth-century has gradually diminished through the centralisation of penal authority in the state, the institutionalisation of penality and concomitant restrictions on individual autonomy. The consequences for liberal democracies is that the state's punishment apparatus exists merely as a symbolic focus for social control, the moral basis upon which it legitimately exercises the power of punishment (the state's consideration for the powers citizens have autonomously ceded to it as part of the social contract) having diminished.

\footnotetext{
${ }^{28}$ An example from England and Wales is the penal policy of 'bifurcation' which has effected a symbolic strengthening of community punishments for reasons associated with crime control, whereas the underlying rationale for change is more to do with saving scarce penal resources.
} 
Similarly, Shearing (2001), when considering the postmodern reconfiguration of state and inter-state governance of security, describes how the tensions within retributive ideology have conditioned the moral framework for developing risk strategies. Apparent lack of autonomy on the part of individual citizens is re-enforced by the shifting contexts of state and inter-state governance (Shearing 2001: 207). In particular, governance is seen as intimately connected to the management of political and economic risk in postmodernity. Penality is a crucial factor in sustaining particular forms of governance and, therefore, in managing such risks, because the structures for punishment are used to support the rationales for control. The implications for punishment are significant in that the conceptualisation of governmentality does not concern itself with the phenomenology of moral actions, or the possibility that its institutions and procedural rules might take generalised notions of individual intention, motivation or blame into account. International forms of governance reflect these characteristics, especially the notion that international structures for punishment are instrumental in sustaining the rationales for control, even if these might include maintaining the economic interests of liberal capitalist states, or supporting global imperialism. Hence, from this perspective, international courts and tribunals cannot be regarded as impartial arbiters between rational formal law and popular justice; rather, they are implicated in the hegemony of international governance and manufacture a selected form of truth and justice (Alvarez, 1998; Drumbl, 2000).

Analogous shifts in the contexts of penality within states subject to international criminal jurisdiction (such as the ICC) ${ }^{29}$ may not necessarily be paralleled globally, yet their relevance for theorising globalised notions of penality must be considered against the rationales and institutional structures established to effect principles of ICJ. This is in order that our understanding of the relationship between local and global penal contexts is couched in terms which are sensitive to the realities of process within and across jurisdictions. Thus, informed links between theory and policy may be expected to provide a reasoned basis for the development of ICJ principles which take into account the global and local consequences of punishment and its enforcement.

In consequence, I argue that it is necessary for ICJ theory to consider the conceptual bases upon which the penality of international punishment might be accorded legitimacy. However, this is far from being a straightforward matter, since legitimacy, being an essentially relative concept, is loaded with fundamental moral and socio-cultural imperatives for criminal justice. For example, legitimacy might be conceptualised in terms which accept the notion of law as transformative in the sense that retributive punishment is necessary to rehabilitate the 'deviant' act and the responsible social group;

\footnotetext{
${ }^{29}$ In the case of the ICC, the situation is further complicated by the doctrine of complementarity. The latter raises difficulties in relation to the operation of human rights paradigms such as the ECHR and its impact on fair trial and evidential issues as well as how one might interpret the proportionality requirements which (arguably) apply to international trial penality. For instance, from which perspective should we consider the increased use of plea bargaining in international criminal trials? How do international tribunals/courts reflect different juridical approaches to plea bargaining in their foundation instruments; are these different rationales relevant to sentencing practice in international tribunals/courts? How do international human rights mechanisms affect international practice and do these differ in their impact from national jurisdictions?
} 
in other words, that expurgation through public retribution is a necessary prelude to closure and the re-establishment of moral order. Alternatively, the transformative or expressive force of legalised punishment may be conceived as a measure of the extent to which the infliction of punishment goes beyond censure in its capacity to convey to citizens that the behaviour with which it deals is morally blameworthy. This approach is dependant upon directing the development of theory away from the notion of legal closure (see Cotterrell, 1998; Nelken, 1998; Banakar, 2000) by permitting interpretations that allow us to make the link between international penal law as a normative expression of moral principles and manifestations of morality in civil society present in particular communities or social groups (Henham, 2001).

\section{The Transformative Power of Discretionary Decision-making}

This section extends the argument so far developed by examining how pluralistic aspirations for ICJ might be realised within a more inclusive form of trial decisionmaking. It begins by speculating about the social reality of sentencing and ICJ by exploring contemporary theoretical and empirical accounts of discretionary decisionmaking, focusing particularly on issues of symbolism and power. Its aim is to evaluate explanations of penal decision-making and reflect upon the extent to which judges as sentencers are instrumental in providing the necessary linkage between political ideology, penal policy and trial outcomes which are perceived as legitimate by trial participants and the wider social audience for ICJ.

There are some important, although as yet unexplored, connections to be made between interactionist accounts of punishment and the internationalisation of sentencing (Lemert, 1972; King, 1978). As far as the criminalisation of behaviour is concerned, there is no doubt that criminological analyses relating to the role of the media in creating and perpetuating moral panics in the context of international crime may offer important insights (Roberts and McMillan, 2003). The notion of deviancy amplification is particularly illuminating in this context, since it is arguable that the use of the international stage to consistently reproduce partial accounts (Alvarez, 1998, 1999) of international conflict which are more often consistent with the version of events portrayed by the powerful and dominant protagonists promotes stereotypes and misconceptions about such conflicts and the motivations of those alleged to have committed international crimes. However, in the present context, the focus is on identifying those aspects of interactionist theory which might enable us to understand more clearly the significance of symbolism in the processual activity of international sentencing and ICJ more generally.

At the micro-level, the symbolic significance of the international sentencing process for individual defendants may lie in its conceptualisation as a ritual of denunciation and degradation, whereby offenders might conceivably internalise the global sentiments of moral condemnation and denunciation expressed by the relevant tribunal to the extent that their own moral sentiments in this respect are altered irrevocably (Lemert, 1972). In this sense, the symbolism of punishment in international criminal courts rests in its 
perception as a personification, conduit or transmitter of international moral sentiment; a message intended equally for the condemners as the condemned. However, because international punishment is relative in its symbolic and real effects, and these do not normally coincide, I would suggest that any conceptualisation of symbolism in this context needs to be developed against notions of 'community' which take full account of the demands for justice of post-conflict societies as well as those of the so-called ‘international community’ of nation states represented by western liberal democracies.

Despite its theoretical and methodological ambivalence, social interactionism provides a potentially useful sensitising paradigm or construct for the analysis of ICJ. It is particularly valuable, as Sudnow (1965) and Cicourel (1968) showed in their seminal analyses of trial processes, for drawing attention to the possibilities for stereotyping and the ways in which procedural rules are systematically redefined in order to satisfy systemic pressures for conformity. Similarly, Skolnick (1966: 27) saw legal rules as 'a context for the behaviour of legal men', so that the study of law in action (such as discretionary decision-making) is seen as essentially concerned with the deconstruction of the meanings attributed to action by social actors, and the interrelationship and transformation of legal principles and rules within legal institutions. Interactionism is, therefore, concerned with understanding the contexts for transformation in the law and process of sentencing, and engages theoretically with the construction of individual and collectively shared experience at different levels and layers of meaning. In practical terms, as King (1978: 218) points out, this suggests a focus on those variables that might influence instrumental behaviour by individuals within the court process; for example, wider contextual reasons for delay, inconvenience and disruption to the defendant's case.

For international sentencing we can speculate that an appreciation of symbolism in courtroom interactions may help to expand our understanding of the forces which shape the differential impacts of the international punishment process. Such enhanced understanding might be developed from an interactionist analysis that sought to account for apparently discriminatory or prejudicial treatment of victims within the international sentencing process. An interactionist perspective may, for example, assist us in identifying points of control within the process where legal rules and procedures actually operate against victims' interests, although procedural norms appears to affirm the opposite (for example, plea bargaining). Hence, whilst this approach might not allow us to draw specific (empirically grounded) conclusions, its focus on elaborating the relationship between the symbolism of structured processes such as punishment and its psychological appropriation by trial participants facilitates our appreciation of the impact of international court process. It might also permit some informed speculation about the extent to which judicial decisions on sentence are structured by procedural rules designed to obfuscate the reality of discriminatory practice, or prejudiced against particular penal orientations which favour restorative justice alternatives.

Postmodern conceptions of law, on the other hand, have consistently challenged claims that its ideological and normative functions might be compatible with notions of justice within western liberal democracies (Fitzpatrick, 1992; Hunt, 1993). In the punishment context, Pratt has described how, utilising Foucault's notion of 'technologies 
of power', the relationship between state moral authority and law is reciprocally created and maintained through the state's control of that body of knowledge which both defines the criminal law and determines the characteristics of those who are labelled as criminal. However, although Foucault may have explored the spatial dimensions of social regulation, as Cohen (1995: 45) suggests, there has been little work on the temporal dimensions of social control; in other words, how states establish the continuity of social control (see Stanley, 2005). Further, Cohen (1993) has also invoked Sykes and Matza's theory of neutralization to analyse government denials of complicity in state crimes, suggesting ways whereby this conception could be further explored to explain how those participating in mass violence and gross human rights violations are able to reconcile their behaviour with their moral consciences.

An important issue arising from these analyses in the present context concerns the relationship between social control and accountability - 'the notion that it is necessary to discover the truth about the past in order to achieve justice in the present'. Cohen $(1995)^{30}$ posits the possibility that structures of international punishment provide a form of social control which is instrumental in negotiating and defining what becomes known as truth and counts as justice. Although alternative structures and processes (such as Truth and Reconciliation Commissions) might provide alternative relative interpretations of truth and justice drawn from different contexts, all purport to achieve a historically definitive version of truth, whether in whole or in part. In the case of international criminal tribunals, such findings of truth are signified by claims of legal closure and legal accountability. $^{31}$

Postmodern or critical legal scholarship also tends to suppress concepts such as selfdeterminism, rational choice and autonomy so that power and social justice are perceived 'as conditioned effects of the autonomous play of discursive formulations' (Salter, 1996: 46). However, Norrie (1996: 395) makes an important distinction between notions of formal and popular justice in suggesting that so-called rational formal law is a mechanism of organised social control supportive of selected moral and political norms, whilst 'popular justice' is incorrectly representing the social and political interests of an abstract individual subject and the rule of law. Norrie appears to be arguing that, in order to understand the relationship between power and social justice, we need to appreciate the reasons for the dialectical connection between the rationale for social control and the phenomenology of individual moral action; in other words, the reasons for the apparent disjunction between the rationales of formal systems (such as punishment structures), the rhetoric of populism, and the experiences and concerns of individual citizens subject to the rule of law.

For international sentencing the development of any decision-making paradigm is complicated by the fact that the judges are drawn from a wide variety of jurisdictional, social and cultural backgrounds. This inevitably affects their perception and interpretation of information and therefore weakens the extent to which they can be

\footnotetext{
${ }^{30}$ Cohen (1995: 48) goes on to develop a paradigm of regimes of continuity.

${ }^{31}$ Christodoulidis (2000) questions whether such reflexive ethical decisions can be reached within a legal context
} 
regarded as sharing comparable understandings and expectations (Pakes, 2004: ch 5). Nevertheless, since judges in the ad hoc tribunals and the ICC have wide discretionary power, the potential exists for the judiciary to individualise sentences and reach beyond the justificatory rhetoric, symbolism and procedural imperatives of retributivism and deterrence to engage with alternative justice paradigms within the constraints of the normative framework in which they operate. The challenge for sentence modelling lies in providing a conceptual vehicle for understanding the relationship between judicial background variables and sentencing behaviour in a comparative context wherein the influences of national and international legal culture impact directly upon processual activity (see further, Findlay and Henham, 2005: ch 8).

\section{Reconciling Differences}

It may be argued that the rationality of punishment and the function of the criminal process are intimately connected and that reason and action are collapsed when the capacity for discretionary decision-making is exercised, since both crystallise within the decision itself. Consequently, values are attributed to the 'facts' that constitute decisions where, as Tamanaha (1997) argues, fact and value merge. Viewed thus, the discretionary decision represents a synthesis of fact and value. Reasons for action are matters of influence and motivation for trial actors that are influenced by system concerns and broader cultural variables. The semantic significance of the synthesis which a discretionary decision represents is a function of the control exercised by procedural norms. However, procedural norms are themselves informed by ideology and policy and may represent competing claims for moral legitimacy. The extent of this depends on the plurality of moral claims and the degree to which competing groups exert power to assert what they perceive as morally legitimate claims. The sentencing decision may therefore be regarded as a corollary of ideology and process. Within the framework for rational action permitted by trial ideology, the exercise of such discretionary power determines outcome. Thus, discretion merges fact and value to correspond with rational objectives for action.

The recursivity of ideology and legitimacy is perpetuated through the synthesis of reason and action as facilitated through the exercise of discretionary power. So described, penality can be conceptualised in terms of either an exclusive or inclusive paradigm. Paradoxically, viewed as an exclusive paradigm, international penality corresponds to Hudson's (2003) notion of a more inclusive (i.e. system bound) universe of ideas, norms, structures and processes through which the dominant ideology of punishment is promulgated. Garland (1990), on the other hand, suggests an inclusive (i.e. socially reflective) paradigm for penality; one that invites us to go beyond the semantics of crime and punishment to engage with pluralities in terms of morality, philosophy and sociology. In other words, Garland invites us to address those moral and social issues that determine the form of the inclusive universe which constitutes international penality. In order to achieve this, I suggest conceptualisations of ICJ need to reconcile the relativism of justice with the semantics of process; in other words, reconcile diverging realities. 
In functional terms, international criminal trials may be seen as arbiters of moral diversity and imperfect regulators of the relative space that exists between competing conceptions of truth and justice. In other words, they regulate the extent to which process decisions can transform rationales for punishment into outcomes which are accorded varying degrees of legitimacy because they reflect differing moral perceptions of what constitutes 'justice' in any particular case. In this sense, international criminal process may be seen to mediate between competing value systems. ICJ exists (if at all) as a reflection of the legitimacy attached to the justification for and performance of that function by the so-called 'global community'. It is a virtual reconciliation of truth and justice for relative consumption, just as it is in domestic contexts. It is ever changing, depending on conflict, communities, and cultures. It can be seen (promoted) as relational (or not); as a positive or negative force for peace (or not), as the case may be.

It may be argued that the moral legitimacy of ICJ could be enhanced by ensuring that the exercise of discretionary power and its outcomes in international trials exist in a context which favours the advancement of communitarian interests and the greater protection of humanity. Such forging of collective forms of justice invites a rationale and potential for integrating retributive and restorative concerns, rather than one promoting ideological hegemony (Findlay and Henham, 2005).

Whilst being more suggestive of non-adversarial procedures, conceptions of restorative justice are not necessarily at variance with deserts-based retributive sentencing paradigms (Dignan and Cavadino, 1996). Furthermore, as Zedner (1994: 248) suggests, both restorative and retributive justice principles are predicated upon notions of individual autonomy, notwithstanding the need to account for the impact of structural inequality, power and social control variables (see, Braithwaite, 2002: ch 6). A potential difficulty, nevertheless, lies in the fact that, whilst retributive proportionality generally equates with the objective assessment of offender culpability and harm, restorative justice is unequivocally conceived in terms proportionate to victim harm, thereby suggesting a response involving social intervention going beyond the normal boundaries of conventional crime and its regulation.

However, it is precisely the need to address such significant structural and ideological concerns which characterises those crimes constituting gross breaches of international humanitarian law. Thus, notions of criminality as reflective of destruction, disintegration, conflict and breakdown go beyond traditional models which equate crime with social injustice. Instead, they lead directly to imperatives for reconstruction and reparation compatible with restorative justice principles aimed at increasing understanding, empowering victims and citizens, and increasing their potential for participation and the resolution of conflict. ${ }^{32}$ Certainly, in the arena of conventional crime, restorative justice principles are seen as potentially capable of re-empowering citizens and a force for social

\footnotetext{
${ }^{32}$ Bush and Folger (1994), for example, would argue that practices like mediation have the potential to transform conflict through empowerment and recognition by citizens of the need to acknowledge and be responsive to the needs of others. See Roberts (2003) for further discussion of the relationship between retributive and restorative justice in the context of ICJ, and also Morris (2002) for a spirited defence of restorative justice, generally.
} 
cohesion (Garland, 2001). In the context of ICJ, the potential for restorative justice is considerable. It lies is its capacity to challenge conventional accounts of the relationship between retributivism and other conceptualisations of penality. This includes recognising that the fulfilment of restorative aspirations are necessary for the resolution of social conflict, and that notions of reparation, reconciliation and reconstruction should inform sentencing outcomes, rather than penality continuing to be compromised by a poorly articulated and largely symbolic retributive ideology which undermines the legitimacy of ICJ.

Accepting that the rationality of international penality should be informed by adopting a more relational approach to the conceptualisation of justice, rather than through the imposition of external rationales foreign to local priorities for truth and restoration, implies that localised notions of the moral legitimacy of punishment ought to be mirrored in national and international penal structures. Seen from this perspective, conceptualising rationales which facilitate the individualisation of sentences in international criminal trials provides an opportunity to develop a relational framework for sentencing which is driven by the need to reconcile the moral justification for criminal process with its perceived moral legitimacy. Consequently, the context for restorative outcomes is conceived through moving beyond conventional conceptualisations that envisage 'communities' purely in terms of victimisation towards paradigms which envisage criminal process as a context for their holistic restoration.

These arguments implicitly recognise that, whilst restorative justice norms may be seen as possessing the transformative power to change the nature and dynamics of trial decision-making, it nevertheless requires an ideological commitment to move in this direction; one that is undertaken for reasons favouring inclusion, integration and resolution rather than factionalism and social conflict. It should nevertheless be recognised that discretionary decisions favouring collective forms of justice are themselves reflective of power exercised within an ideologically and normatively structured environment. Consequently, the task of balancing the interests of offenders, victims and communities (global and local) cannot be reconciled in terms which promote peace and reconciliation without processual norms of access being promulgated and adhered to, and conduct norms being developed based on the new rationality.

The penality of ICJ will not be perceived as fair and just merely through a strengthening of respect for procedural norms. On the contrary, the crucial signifier of legitimacy can only be achieved by ensuring that the structures and norms of international criminal process are reinforced by a rationality which promotes a normative framework flexible enough to accommodate outcomes and strategies sufficiently meaningful for all those with claims to justice in post-conflict societies.

Acknowledging the relativity of justice does not render it meaningless. Justice is all about closure, whether achieved through operationalising retributive or restorative ideologies, or a combination of these or other rationales. The ability of trial process to assimilate and give effect to different perceptions of what is, and what will constitute, justice in post-conflict societies is what matters. International criminal trials should not 
simply legitimise partisan versions of truth because their decision-making processes implement particular ideologies and norms. Decision-making processes should be capable of objectifying the subjective realities of trial participants' experiences in ways which are meaningful, impartial and consistent (Rogers and Erez, 1999). Processual justice which remains symbolic, rhetorical and partial should not be regarded as morally justifiable by the majority of nation states. For international criminal process to command universal respect its legitimacy must be derived from the fact that it has moral integrity in the eyes of all significant parties to a conflict, not simply those exercising hegemonic power. $^{33}$

In conclusion, I have argued that normative flexibility positioned within parameters for rational decision-making which are geared to produce constructive and relevant outcomes will gradually promote the development of a penality for international criminal trials which is responsive and creative, and whose instrumental capacity can be exploited constructively by judges in the exercise of their discretionary decision-making powers to satisfy the relative demands of victims and different communities of justice in postconflict societies. ${ }^{34}$ Only in this way will ICJ ever come to be perceived by significant others as just and fair.

\section{References}

Acton H. B. (ed.) (1972) John Stuart Mill: Utilitarianism, Liberty, Representative Government London: J. M. Dent \& Sons Ltd

Akhavan P. (2001) 'National Perspectives and Reservations' Paper presented to the International Conference, From a Culture of Immunity to a Culture of Accountability: International Criminal Tribunals, the International Criminal Court, and Human Rights Protection, University of Utrecht, Netherlands, 26-28 November.

Alvarez J E (1998)'Rush to Closure: Lessons of the Tadic Judgment’ Michigan Law Review 96: 2031-2122 Alvarez J E (1999) 'Crimes of States/Crimes of Hate: Lessons from Rwanda’ Yale Journal of International Law 24: 365-483

Banakar R (2000) 'Reflections on the Methodological Issues of the Sociology of Law' Journal of Law and Society 27: 273-295

Baumann Z (1993) Postmodern Ethics Oxford: Basil Blackwell

Braithwaite J (2002) Restorative Justice and Responsive Regulation Oxford: Oxford University Press

\footnotetext{
${ }^{33}$ In reconciling claims to legitimacy we should also recognise that norms do not necessarily predate interaction and thus determine its sociological significance. Rather norms may be partially constructed in the process of interaction and hence the processing and labelling of individuals through international forms of punishment could be seen more constructively as a stage in norm construction which aims to accommodate local and global justice.

${ }^{34}$ For further development of these ideas, see Findlay and Henham (2005: ch 8).
} 
Beccaria C (1995) Of Crimes and Punishments and other writings [Dei Delitti e delle Pene] edited by R Bellamy and translated by R Davies with V Cox and R Bellamy Cambridge: Cambridge University Press. First published in 1764.

Bell J (2001) French Legal Cultures London: Butterworths

Bush R and Fogler J (1994) The Promise of Mediation: Responding to Conflict through Empowerment and Recognition San Francisco: Jossey-Bass Publishers, 1994, 84-85.

Cicourel A (1968) The Social Organisation of Juvenile Justice New York: John Wiley

Christodoulidis E A (2000) 'Truth and Reconciliation as Risks' 9 Social \& Legal Studies 179-204

Cohen S (1993) 'Human Rights and Crimes of the State: The Culture of Denial' Australian and New

Zealand Journal of Criminology 26: 97-115

Cohen S (1995) 'State Crimes of Previous Regimes: Knowledge, Accountability and the Policing of the

Past' Law and Social Inquiry 20: 7-50

Cotterrell R B M (1998) 'Why Must Legal Ideas Be Interpreted Sociologically?’ Journal of Law and

Society 25: 171-192

Cotterrell R B M (1999) Emile Durkheim: Law in a Moral Domain Edinburgh: Edinburgh University Press Dignan J and Cavadino M (1996) 'Towards a Framework for Conceptualising and Evaluating Models of

Criminal Justice from a Victim’s Perspective’ International Review of Victimology 4: 153-182

Drumbl M (2000) 'Punishment, Postgenocide: From Guilt to Shame to Civis in Rwanda' New York

University Law Review 75: 1221-1326

Durkheim E (1982) The Rules of Sociological Method and Selected Texts on Sociology and its Method

trans. by W D Walls London: Macmillan

Durkheim E (1984) 'Two Laws of Penal Evolution' in S Lukes and A Scull (eds) Durkheim and the Law

Oxford: Basil Blackwell, 101-132

Findlay M and Henham R (2005) Transforming International Criminal Justice: retributive and restorative justice in the trial process Cullompton: Willan Publishing

Finnis J (1980) Natural Law and Natural Rights Oxford: Oxford University Press

Fitzpatrick P (1992) The Mythology of Modern Law London: Routledge

Garland D (1990) Punishment and Modern Society Oxford: Clarendon Press

Garland D (1996) 'The Limits of the Sovereign State: Strategies of Crime Control in Contemporary

Society’ British Journal of Criminology 36: 445-471

Garland D (2001) The Culture of Control Oxford: Oxford University Press

Green E (1961) Judicial Attitudes in Sentencing London: Macmillan.

Gross H (1979) A Theory of Criminal Justice New York, Oxford University Press

Hampton J (1988) 'The Retributive Idea' in J Murphy and J Hampton Forgiveness and Mercy Cambridge:

Cambridge University Press

Habermas J (1992) 'Discourse, ethics, law and sittichkeit' in P Dews (ed) Autonomy and Solidarity:

Interviews with Jurgen Habermas London: Verso, revised ed.

Hart H L A (1968) Punishment and Responsibility: Essays in the Philosophy of Law Oxford: Oxford

University Press

Henham R (2000) 'Sentencing Theory, Proportionality and Pragmatism’ International Journal of the

Sociology of Law 28: 239-263

Henham R (2001) 'Theory and Contextual Analysis in Sentencing' International Journal of the Sociology

of Law' 29: 253-276

Henham R (2003) ‘The Philosophical Foundations of International Sentencing' Journal of International

Criminal Justice 1: 64-85

Henham R (2005) Punishment and Process in International Criminal Trials Aldershot: Ashgate

Hogarth J (1971) Sentencing as a Human Process Toronto: University of Toronto Press

Hood R G (1972) Sentencing the Motoring Offender London: Heinemann.

Hudson B (1996) Understanding Justice: an Introduction to ideas, perspectives and controversies in

modern penal theory (Buckingham: Open University Press, $1^{\text {st }}$ ed.

Hudson B (2003) Understanding Justice: an Introduction to ideas, perspectives and controversies in modern penal theory Buckingham: Open University Press, $2^{\text {nd }}$ ed.

Hunt A (1993) Explorations in Law and Society: towards a constitutive theory of law London: Routledge King M (1978) 'A Status Passage Analysis of the Defendant's Progress through the Magistrates' Court'

Law and Human Behaviour 2: 167-221 
Kiza E and Rohne R (2005) Victims' Expectations: The International War-Victim Survey Freiburg: Max Planck Institute for Foreign and International Criminal Law

Lemert E M (1972) Human Deviance, Social Problems and Social Control Englewood Cliffs, New Jersey: Prentice Hall, $2^{\text {nd }}$ ed.

Levinas E (1989) 'Ideology and Idealism' in S Hand (ed) The Levinas Reader Oxford: Basil Blackwell Lyotard J-F (1988) The Differend: Phrases in Dispute Manchester: Manchester University Press Morris A (2002) 'Critiquing the Critics: A Brief Response to Critics of Restorative Justice' British Journal of Criminology 42: 596-615

Morrison W (1997) Jurisprudence: From the Greeks to Post-Modernism London: Cavendish Nelken D (1998) ‘Blinding Insights?: The Limits of a Reflexive Sociology of Law’ Journal of Law and Society 25: 407-426

Norrie A (1996) 'From Law to Popular Justice: Beyond Antinomialism' Social \& Legal Studies 5: 383-404 Norrie A (2000) Punishment, Responsibility and Justice Oxford: Oxford University Press

Pakes F (2004) Comparative Criminal Justice Cullompton: Willan Publishing

Pratt J (1995) 'Dangerousness, Risk and Technologies of Power' Australian and New Zealand Journal of Criminology 28: 3-31

Pratt J (1998) 'Towards the 'Decivilizing' of Punishment' Social \& Legal Studies 7: 487-515

Radzinowicz L (1966) Ideology and Crime London: Heinemann

Raz J (1979) The Authority of Law: Essays on Law and Morality Oxford: Oxford University Press, 1979

Raz J (1994) Ethics in the Public Domain: Essays in the Morality of Law and Politics Oxford: Clarendon Press, rev. ed.

Roche D (2005) 'Truth Commissions, Amnesties and the International Criminal Court' British Journal of Criminology 45: 565-581

Roberts P (2002) 'On Method: The Ascent of Comparative Criminal Justice' Oxford Journal of Legal

Studies 22: 539-561

Roberts P (2003) 'Restoration and Retribution in International Criminal Justice' in A von Hirsch et al.

Restorative Justice and Criminal Justice: Competing or Reconcilable Paradigms?’ Oxford: Hart

Publishing

Roberts P and McMillan N (2003) ‘For Criminology in International Criminal Justice’ Journal of

International Criminal Justice 1: 315

Rogers L J and Erez E (1999) 'The Contextuality of Objectivity in Sentencing among Legal Professionals in South Australia' International Journal of the Sociology of Law 27: 267-286

Salter M (1996) 'The Impossibility of Human Rights within a Postmodern Account of Law and Justice' Journal of Civil Liberties 1: 29-66

Sentencing Guidelines Council (2004) Draft Guideline-1: Reduction in Sentence for a Guilty Plea available online at http://www.sentencingguidelines.gov.uk/draftguidelines/guiltypleas/foreword.html

Shearing C (2001) 'Punishment and the Changing Face of the Governance' Punishment and Society 3: 203220

Skolnick J H (1966) Justice Without Trial New York: John Wiley

Simmel G (1955) Conflict New York, The Free Press

Stanley E (2005) 'Truth Commissions and the Recognition of State Crime' British Journal of Criminology 45: 582

Sudnow D (1965) 'Normal Crimes: Sociological Features of the Penal Code in a Public Defender Office'

Social Problems 12: 255-276

Tamanaha B Z (1997) Realistic Socio-Legal Theory Oxford: Clarendon Press

Tata C (1997) 'Conceptualisations and Representations of the Sentencing Decision Process' Journal of Law and Society 24: 395-420

von Hirsch A (1993) Censure and Sanctions Oxford: Clarendon Press

Walker N (1972) Sentencing in a Rational Society Harmondsworth: Penguin

Zedner L (1994) ‘Reparation and Retribution: Are they Reconcilable?’ 57 Modern Law Review 226-250 